\title{
Conjoint Analysis of U.S. Consumers' Preference for Elderberry Jelly and Juice Products
}

\author{
Phillip M. Mohebalian ${ }^{1}$ and Francisco X. Aguilar \\ University of Missouri, Department of Forestry, 203 ABNR Building, \\ Columbia, MO 65211
}

Mihaela M. Cernusca

University of Missouri, Center for Agroforestry, 203 ABNR Building, Columbia, MO 65211

Additional index words. Sambucus sp., conjoint analysis, marketing strategies

\begin{abstract}
This study is the first of its kind in eliciting U.S. consumer preferences for elderberry juice and jelly products. An online survey collected self-reported information from 1043 U.S. residents. Results of a conjoint analysis suggest elderberry products that disclose qualified health claims and are produced locally were the best positioned to compete for greater shares in the jelly and juice product markets. Although consumers were $27 \%$ less likely to purchase elderberry jelly and $23 \%$ less likely to purchase elderberry juice relative to products containing competing fruit types, ceteris paribus, the fruit type product attribute determined only $9 \%$ of jelly and $13 \%$ of juice stated purchasing decision. More important than fruit type, consumers valued product price, disclosure of health claims, and origin. Consumers were 3.7 times more likely to choose locally produced jelly products than imported jelly and twice as likely to select products disclosing health claims compared with jelly products without claims. Likewise, consumers were 3.3 times more likely to choose locally produced juice products than imported juice products and 2.1 times more likely to select juice products with health claims than without. Our results indicate that an introductory strategy that combines the strength of preferences for locally produced products along with the disclosure of health claims at a competitive price can be an important tool in expanding the market for elderberry products in the United States.
\end{abstract}

Cultivation of the North American elderberry (Sambucus canadensis) has increased significantly in recent years as a result of growing interest for elderberry juice and jelly products (Cernusca et al., 2011). Although the elderberry industry appears poised for major expansion, its development is hampered in part as a result of the risks associated with limited knowledge about consumer preferences for a new product and how these compare with preferences for existing ones (Cernusca et al., 2011). Successfully introducing and expanding consumption of new products such as elderberry juice or jelly into well-established and highly competitive markets requires understanding of consumer preferences (Dolan, 2001). Firms introducing new elderberry products into competitive markets need current and comprehensive information about consumer preferences to develop products most likely to capture market share.

Information about consumer preferences can be distilled by breaking products down into their component attributes. The quantitative

Received for publication 9 Oct. 2012. Accepted for publication 24 Jan. 2013.

Partial funding for this project was provided by the Sustainable Agriculture Research and Education (SARE) grant, LNC10-324.

${ }^{1}$ To whom reprint requests should be addressed; e-mail Pmmrn3@mail.missouri.edu. measurement of each attribute function in generating overall consumer use for the product is essential to designing products that maximize consumer demand (Green and Srinivasan, 1990). Consumer preference information can also help firms selling elderberry products to develop specific strategies targeting niche markets and increase sales through product diversification. This study evaluated consumers' stated preferences for selected elderberry product attributes in an effort to generate information that can be used to design strategies for the promotion of elderberry products in the United States.

Marketing strategies that promote elderberry products are often founded on associated health benefits of consumption disclosed through product labels. Although little scientific research has been conducted on the North American elderberry, its close relative, the European elderberry (Sambucus nigra), is an excellent source of bioflavonoids and anthocyanins, which give the fruit a diverse range of antioxidant properties (Barak et al., 2001). Lee and Finn (2007) found both species to contain cyaniding-based anthocyanins and suggest breeding programs to enhance these properties. In addition, recent medical studies have found the consumption of European elderberry strengthens immune response to viral infection (Roschek et al., 2009; Uncini Manganelli et al., 2005). Assessment of the oxygen radical absorbance capacity score that estimates total antioxidant concentration indicates that elderberries are a superior source of antioxidants compared with other fruits such as cranberry (Vaccinium macrocarpon) or grapefruit (Citrus paradisi). The latter fruits have been heavily marketed to consumers for their potential health benefits (USDA Agriculture Research Service, 2007). Health concerns are major issues among U.S. consumers partly linked to substantial increases in lifestyle-related diseases such as obesity, heart disease, diabetes, and cancer (U.S. Centers for Disease Control and Prevention, 2010). According to Glanz et al. (1998), U.S. consumers rank the health benefits of the foods they eat as the third most important factor contributing to purchasing choices, after taste and cost.

Another strategy for marketing elderberry products is to increase sales by promoting locally produced elderberry products. Locally produced products are defined as products purchased from within the boundaries of the state in which they were grown or produced and transported no more than 400 miles. The North American elderberry has great potential for sale as a local product because its native habitat encompasses the majority of the North American continent (Charlebois et al., 2010). As a case in point, U.S. demand for locally grown food has seen substantial nominal growth as denoted by growth in direct-toconsumer marketing from \$551 million in 1997 to $\$ 1.2$ billion in 2007 (USDA Economic Research Service, 2010). Along with this increase in sales, the number of farmers' markets around the nation has more than doubled from 2750 in 1998 to a total of 5274 in 2009 (USDA Economic Research Service, 2010).

Given the need for up-to-date and detailed information on consumer preferences for elderberry products, this study investigated current U.S. consumer elderberry product consumption habits and parameterized preferences for two elderberry products: jelly and juice. Our research argument is that elderberry products can enter the competitive market of jelly and juice products in the United States if consumer preferences are properly investigated and well understood. Specific objectives were to: 1) evaluate selected product attributes and their corresponding importance to product choice; 2) contrast preferences for elderberry with well-established products to explore market competitiveness; and 3) evaluate consumer price sensitivity toward elderberry products. Ultimately, we aimed to suggest strategies for introduction of jelly and juice elderberry products by identifying product profiles most likely to trigger consumer selection in established U.S. markets. Suggested marketing strategies are based on findings of a conjoint analysis of elderberry product attributes.

\section{Theoretical Framework}

This study relied on economic choice theory to investigate and better understand consumer preferences for elderberry products. 
Choice theory originated in the field of psychology that developed methods to evaluate human behavior. In its early stages of development, choice theory was primarily used to create models to explain the outcomes of physiological experiments in which subjects were presented stimulus to illicit deterministic behavioral outcomes (Anderson et al., 1992). Thurstone (1927) first applied choice theory to quantitatively compare choice alternatives and social values based on criminal offense and corresponding judicial sentences. Modern use of choice theory is applied in economic and marketing studies to model consumer behavior. McFadden (1986) explains that at the core of choice theory sits the belief that consumers will act and make decisions in ways that optimize use and preference. Choice theory attempts to measure consumer decisions as a function of the products and available attribute combinations, the characteristics that define the consumer, and unexplainable variation of choice associated with the individual (McFadden, 1974). By including these three components, use derived from product consumption may be expressed as:

$$
U=V_{(\mathrm{s}, \mathrm{x})}+E_{(\mathrm{s}, \mathrm{x})},
$$

where $U$ is the use generated from a product, $V$ is associated with explainable components of the choice, characteristics that identify the consumer, and what product they are buying, $E$ represents random unexplained variation, s denotes the universe of choice objects, and $\mathrm{x}$ the universe of characteristics that describe the decision-maker (Louviere et al., 2010).

\section{Materials and Methods}

Conjoint analysis design. An online survey was developed with the purpose of sampling households throughout the United States based on their purchasing habits and preferences for elderberry products. The survey implemented a conjoint analysis (CA) to determine consumer preference for elderberry jelly and juice products. These two products were identified as the most common elderberry products purchased in the U.S. market based on exploratory research by Mohebalian (2011) and later confirmed in this study. CA techniques measure use or satisfaction from a product with multiple attributes (Green and Srinivasan, 1990). CA continues to be a common method used to model choice behavior in consumer preference research (e.g., Aguilar et al., 2009a,b; Lonial et al., 2000; Teratanavat and Hooker, 2005). Jelly and juice product attributes and corresponding levels included in the CA design were selected based on their relevance following a literature and market review (e.g., price, fruit type, product origin, and health claims) and exploratory research by Mohebalian (2011) that validated the proposed design. A focus group was conducted to refine an early draft of the survey instrument. The focus group was comprised of five elderberry consumers and four research monitors. Participants included both male and female Missouri residents between the ages of 26 and 55 years. Focus group participants were identified at the University of Missouri Agroforestry Center's 2010 Chestnut Roast Festival based on their expressed interest in elderberry products. As a result of the focus group, two versions of the survey were created, one for jelly and the other for juice products. These distinct versions, instead of a single survey instrument inquiring about jelly and juice preferences, were selected to avoid respondent fatigue and to focus on specific product markets.

Selected product attributes in both juice and jelly CA designs included 1) fruit type; 2) price level; 3) product origin; and 4) disclosure of a health claim. The attribute fruit type was included in the design to measure competition between elderberry and similar products containing alternative fruit types. The jelly version of the survey compared elderberry against its closest competitor, blackberry (Rubus sp.), because this was found to appeal to a similar consumer segment (Mintel Group, 2010). Elderberry was also compared against a status quo jelly product, the most popular jelly fruit type in the market, grape (Vitis vinifera), when excluding strawberry (Fragaria ananassa) (Mintel Group, 2010). Although strawberry-flavored jelly spreads are consumed by a larger portion of the U.S. households, grape was identified during the focus group to be the fruit more closely associated to elderberry jelly based on taste, texture, and coloring (Mohebalian, 2011). The juice version of the survey identified pomegranate (Punica granatum) juice as the closest competitor to elderberry and cranberry juice as the status quo fruit type in the juice market, excluding orange (Citrus sinensis) and apple (Malus domestica) (Mintel Group, 2011). Remaining CA attributes (price, product origin, and disclosure of health claim) were identified during the initial exploratory stage of research based on their importance to consumers and representation of their respective markets (Mohebalian, 2011). Attribute levels were: the price of the jelly/juice product $(\$ 3, \$ 4$, and $\$ 5)$; where the product originated from (locally, in the United States, or imported); and whether the product displayed a qualified health claim on its label. The survey identified local products as those products purchased from within the boundaries of the state in which it was grown or produced and transported no more than 400 miles from where it was purchased. Health claims identified the product's ingredients as being high in antioxidants and supporting the immune system (USDA Agriculture Research Service, 2007).

The CA design resulted in a total of 36 possible product profiles. A factorial design including all possible profiles would have been $100 \%$ efficient but required at least 18 paired survey questions. To reduce the effects of respondent fatigue, the study implemented a fractional factorial design instead. Following Rambonilaza and Dachary-Bernard (2007) and using SAS software (SAS Institute Inc.,
2008), the factorial design for the product profiles was constructed with $99.82 \%$ design efficiency and a minimal design error of 0.64 . With only 18 product profiles to select from in pairs, the questions were reduced to nine choices with the status quo product as the third option in each question (Louviere et al., 2000). The nine CA questions were presented to survey participants using a choice-based technique in an effort to closely mimic a shopping experience in which consumers select one of an array of available products. The version of the survey focusing on the jelly product framed the product selection process using the following verbiage: "Imagine you are now in a gourmet specialty foods store, shopping for a recyclable 12-ounce container of gourmet elderberry jelly. You find that there are only three options for gourmet jelly products to choose from. Please review the questions below which represent choices of hypothetical labels of gourmet products you find at the store. For each of the following questions please select the product that you would most likely purchase in this situation." An example of the stimulus used as the first CA question in the jelly version of the survey is presented in Figure 1.

It is worth mentioning some of the limitations inherent to the methods used in this study. First, the use of CA in an experimental setting is an effective tool to measure consumer preferences but is limited in that it can only capture the stated preferences of consumers as opposed to observed behavior. This is a limitation raised by Horowitz and Louviere (1993) among others; however, the use of stated preferences is the only effective way to elicit consumers' behavior when dealing with hypothetical products. Moreover, stated preferences provide important information about the cognitive decision processes that ultimately drive behavior intention and choice (McFadden, 1986). Second, the use of a survey-based tool limited our ability to record reactions and preferences for the sensory taste of the selected elderberry products. Taste is often cited as a primary factor in determining final consumer decisions (Glanz et al., 1998). Although taste would be a valuable asset for understanding how consumers would react to elderberry products post-consumption, our results can still be used to estimate initial purchase preferences when elderberry and competing products are available to consumers. In this sense, our study mimics how the U.S. population would react and what market conditions would be the main drivers to induce consumers to select products not widely available in the market (e.g., Baker and Burnham, 2001). Despite these limitations, our findings can be instructive in designing market introduction strategies. Finally, this study focused solely on the demand side of the market by investigating consumer preferences. Supply-side issues such as costs of production were not included in this analysis and should be further evaluated.

Data collection. The survey instruments were deployed using Qualtrics (Qualtrics 


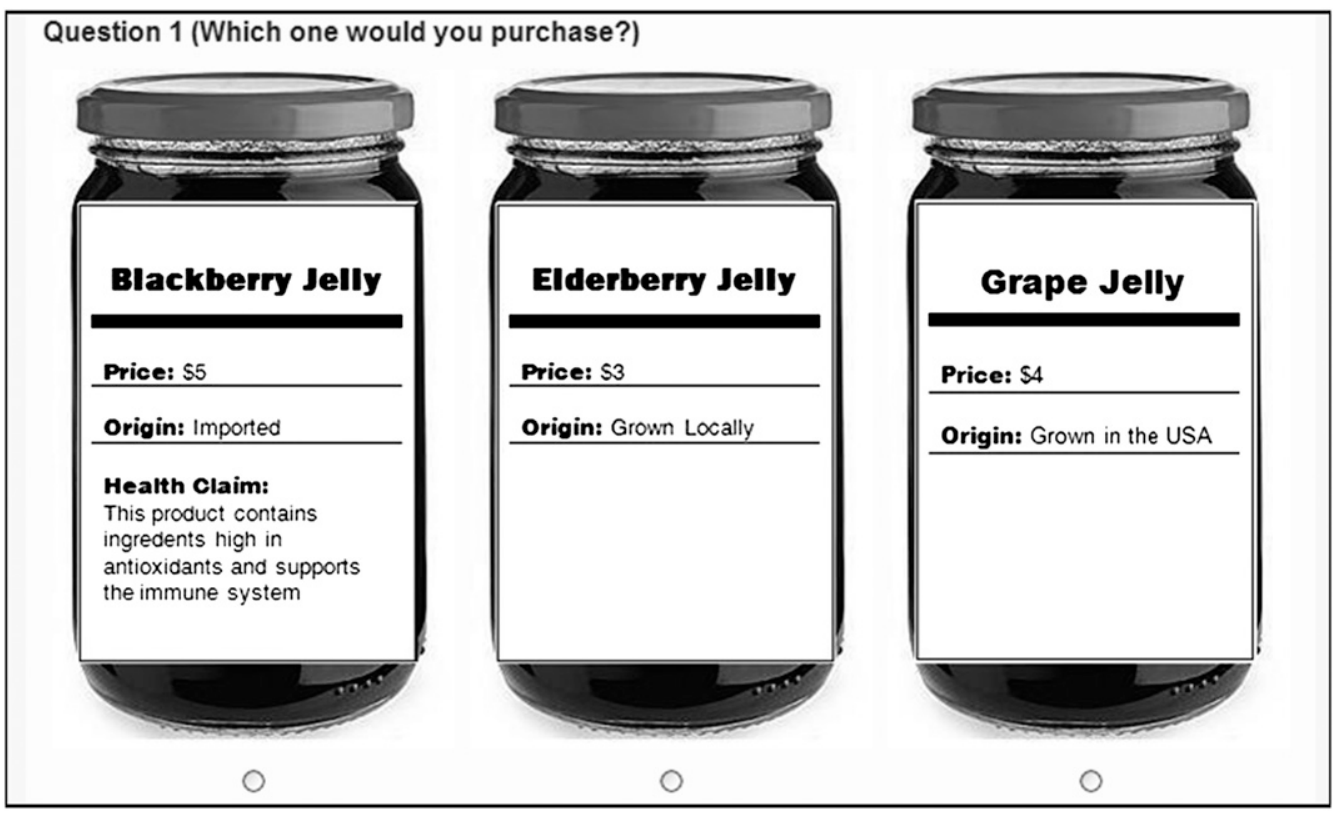

Fig. 1. Choice-based conjoint analysis stimuli illustrating the comparison of three 12-ounce glass jars of jelly with different product labels.

Laboratories Inc., Provo, UT), an Internet survey design program and distributed through Survey Sampling International (SSI) in Aug. 2011. Participants were sampled from a panel of U.S. consumers and received incentives for participation as administered by SSI. Participants were not selected based on familiarity with elderberry products nor provided information on elderberry products before being selected. All content of the survey instrument received approval from the University of Missouri's Institutional Review Board before its distribution. The survey instruments were pretested locally in the state of Missouri among local health food store customers (Mohebalian, 2011). Each response was identified as having originated from a different respondent with no matching internet protocol (IP) addresses among the sample.

Econometric analysis. The CA was analyzed using a conditional logit regression (McFadden, 1974, 1986). Two separate conditional logit models were developed for the purpose of independently analyzing the results of both the juice and jelly versions of the survey. The dependent variable used in the model was a binary response $(1=$ product chosen, $0=$ not chosen). The model included categorical variables based on the fruit types provided, whether the product contained a health claim and the origin of production. The competitor fruit type (e.g., blackberry for jelly and pomegranate for juice), imported, and products without health claims were identified as the base levels for each categorical variable and excluded to avoid perfect collinearity. The price variable was continuous. Odds ratios were calculated from exponentiation of the model's coefficients (Long and Freese, 2006). Relative importance of each attribute in determining consumer purchasing decisions was estimated from the model's coefficients (Baker, 1999; Simonne et al., 2006). Relative importance was calculated based on methods similar to Harrison et al. (2002):

$$
\mathrm{RI}_{i}=\left(\text { range }_{i} * 100\right) / \sum(\text { ranges }),
$$

where RI is the relative importance calculated for product attribute $i$. The range was found by subtracting the highest and lowest coefficients for each attribute and then dividing by the aggregate range for all attributes in the model and multiplying by 100 .

In addition to the original product attributeonly models, additional models were calculated for both survey versions including interaction variables with selected consumer information (Aguilar et al., 2009a; Veisten, 2007; Wessells et al., 1999). The inclusion of demographic interaction variables can increase model accuracy by including personal characteristics of the consumer, which often play an important role in determining choice behavior (Hu et al., 2009). The interaction variables were created by multiplying the original product attribute variables by demographic variables (Chunrong and Norton, 2003). Demographic variables included gender, income, and age. Gender was measured as a binary variable with female equal to 1 and 0 otherwise. Total annual household income was measured on a 14-point ordinal scale $(1=$ less than $\$ 10,000,2=\$ 10,000$ to $\$ 14,999,3=\$ 15,000$ to $\$ 24,999,4=\$ 25,000$ to $\$ 34,999,5=\$ 35,000$ to $\$-49,999,6=$ $\$ 50,000$ to $\$ 74,999,7=\$ 75,000$ to $\$ 99,000$, $8=\$ 100,000$ to $\$ 124,000,9=\$ 125,000$ to $\$ 149,000,10=\$ 150,000$ to $\$ 174,999$, $11=\$ 175,000$ to $\$ 199,999,12=\$ 200,000$ to $\$ 224,999,13=\$ 225,000$ to $\$ 249,999$, $14=\$ 250,000$ and over). Age was measured on a 6 -point scale $(1=18$ to 24 years, $2=25$ to 34 years, $3=35$ to 44 years, $4=45$ to 54 years, $5=55$ to 64 years, $6=65$ years). The two scales were adapted from the U.S. Census Bureau (2000).

The potential market shares for jelly and juice products for two different scenarios were estimated based on specific marginal effects of incremental price premiums as performed by Aguilar and Cai (2010) and explained in Green and Srinivasan (1990). The percent market share at different price levels was estimated by comparing elderberry jelly and juice products against competitive fruit choice alternatives (blackberry jelly and pomegranate juice) and the status quo options (grape jelly and cranberry juice) based on estimated probabilities derived from the conditional logit model. The first scenario compared elderberry juice and jelly products containing health claims. In this first scenario, market shares for elderberry products containing health claims and produced locally (purchased from within the boundaries of the state in which it was grown or produced and transported no more than 400 miles to where it is purchased) and elderberry products displaying health claims but imported (produced outside the United States) were estimated. In the second scenario, market shares of locally produced elderberry juice and jelly products with and without health claims were estimated. The market shares in both scenarios were compared incrementally based on a single dollar increase in price from $\$ 1$ to $\$ 7$. The base price for both jelly and juice products was placed at $\$ 4$, which represented market cost to purchase the status quo juice or jelly product option at the time of the study. As the product price increased by $\$ 1$ increments past the $\$ 4$ base price, each additional unit increase in price represented hypothetical price premiums for which corresponding market shares were estimated. 


\section{Results}

Sample description. The study collected a total of 1043 completed responses from U.S. participants. Version 1 of the survey focusing on jelly products received 535 responses. Version 2, focusing on juice products, received 508 responses. Demographic data for the survey participants were compared with data from the 2000 U.S. Census, the most recent data available at the time of the study, as an indication of how representative our sample is of average U.S. consumers (Table 1). Other than the difference in estimates for rural and urban residence, the data collected on marital status, average number of children, education, income, ethnic background, and the regional distribution of the survey sample fitted well with 2000 U.S. Census data. The study sample included a greater proportion of individuals living in rural residences relative to the U.S. Census. This difference can be explained by the definition of urban and rural used to measure these variables. The 2000 Census defined urban as "groups or blocks that have a population density of at least 1,000 people per square mile and surrounding census blocks that have an overall density of at least 500 people per square mile" (U.S. Census Bureau, 2000). Our definition identified urban as those respondents living nine or fewer miles from a population of 50,000 people or greater. Fifty-four percent of the participants were female. The participants' ages ranged from 18 to 86 years. The average age of respondents was 48 years old. It is worth mentioning that the sum of percentages for ethnic background of survey respondents is not equal to 100 . This is true for both the census data and the data collected in the study.

Of the total sample, when asked about familiarity with elderberry products, 33\% responded affirmatively. Of this number, $21 \%$ reported having consumed elderberry products, and $17 \%$ also reported having purchased elderberry products. Elderberry products most frequently purchased included elderberry juice (18\%) followed by elderberry jelly (17\%) and elderberry wine (15\%). These products were most frequently purchased in grocery stores (32\%), farmers' markets $(25 \%)$, and health food stores $(20 \%)$.

Consumer elderberry jelly preferences. The results of the conditional logit model for survey Version 1 (jelly products) are presented in Table 2. The model included 13,548 observations and was found to be statistically significant with a $P$ value for the likelihood ratio test less than 0.001 . The regression included all categorical variables with the exception of the continuous price variable. Coefficients and odds ratios in the regression are relative to the base levels for the regression, which included blackberry, imported, and without a health claim. The regression found all variables to be significant with $P$ values less than 0.001 .

The results presented in Table 2 show that variables for price, elderberry, and grape jelly have negative coefficients. Hence, holding all other attributes constant, the inclusion of

Table 1. Summary of demographic information for the 1043 survey participants compared with the U.S. population as measured by the 2000 U.S. Census.

\begin{tabular}{|c|c|c|}
\hline Total survey respondents & Survey sample (2011) & U.S. population (2000) \\
\hline Gender (female) & $54.00 \%$ & $50.90 \%$ \\
\hline \multicolumn{3}{|l|}{ Age (years) } \\
\hline $18-24$ & $10.14 \%$ & $14.54 \%$ \\
\hline $25-34$ & $17.68 \%$ & $21.26 \%$ \\
\hline $35-44$ & $12.75 \%$ & $12.25 \%$ \\
\hline $45-54$ & $18.55 \%$ & $20.18 \%$ \\
\hline $55-64$ & $24.15 \%$ & $12.98 \%$ \\
\hline 65 and over & $16.71 \%$ & $18.79 \%$ \\
\hline \multicolumn{3}{|c|}{$\begin{array}{l}\text { How far do you live from an urbanized } \\
\text { area of at least } 50,000 \text { people? }\end{array}$} \\
\hline Urban & $53.21 \%$ & $77.62 \%$ \\
\hline Rural & $46.79 \%$ & $22.38 \%$ \\
\hline \multicolumn{3}{|c|}{$\begin{array}{l}\text { How many children are currently living } \\
\text { with you (no. of persons)? }\end{array}$} \\
\hline Average per family & 0.54 & 0.90 \\
\hline Average with children & 1.83 & 1.86 \\
\hline \multicolumn{3}{|l|}{ Marital status } \\
\hline Married & $46.88 \%$ & $54.40 \%$ \\
\hline Unmarried & $53.12 \%$ & $45.60 \%$ \\
\hline \multicolumn{3}{|l|}{ Education } \\
\hline High school & $52.40 \%$ & $49.60 \%$ \\
\hline College degree & $33.84 \%$ & $21.80 \%$ \\
\hline Graduate degree & $8.34 \%$ & $8.90 \%$ \\
\hline Other & $5.37 \%$ & $19.70 \%$ \\
\hline \multicolumn{3}{|l|}{ Household income } \\
\hline Less than $\$ 35,000$ & $36.73 \%$ & $41.40 \%$ \\
\hline$\$ 35,000-\$ 50,999$ & $16.40 \%$ & $16.50 \%$ \\
\hline$\$ 51,000-\$ 75,999$ & $17.45 \%$ & $19.50 \%$ \\
\hline$\$ 76,000-\$ 100,000$ & $10.07 \%$ & $10.20 \%$ \\
\hline$>\$ 100,000$ & $19.35 \%$ & $12.30 \%$ \\
\hline \multicolumn{3}{|l|}{ Ethnic background } \\
\hline African American & $36.73 \%$ & $12.60 \%$ \\
\hline Asian & $4.60 \%$ & $4.80 \%$ \\
\hline Hispanic/Latino & $4.41 \%$ & $16.30 \%$ \\
\hline Native American & $1.53 \%$ & $0.90 \%$ \\
\hline White & $80.92 \%$ & $75.10 \%$ \\
\hline \multicolumn{3}{|l|}{ U.S. region } \\
\hline Western & $19.46 \%$ & $22.46 \%$ \\
\hline Central & $22.44 \%$ & $22.88 \%$ \\
\hline South & $39.31 \%$ & $35.62 \%$ \\
\hline Northeastern & $18.79 \%$ & $19.04 \%$ \\
\hline
\end{tabular}

each of these attributes resulted in a decreased probability of stated purchase compared with their base levels. If the jelly product were to be made from elderberry, there was a $27 \%$ lower likelihood of that product being chosen with respect to the base level of blackberry jelly, ceteris paribus. The same conclusion can be made for grape jelly with $20 \%$ less probability and price with a $45 \%$ less probability when controlling for all other variables.

Local products, products that were produced in the United States, and products with health benefit claims all resulted in positive coefficients. Products of local origin were 3.68 times more likely to be selected than imported products followed by U.S. origin products, which were 2.76 times more likely to be chosen than imported products when controlling for all other variables. Products with health claims were 2.02 times more likely to be selected by survey participants than products without health claims when controlling for all other variables. The relative importance was greatest for the product's origin (e.g., local, U.S., imported) (37\%) followed by price $(34 \%)$, health claims $(20 \%)$, and the least important factor was the type of fruit in the product $(9 \%)$.
The demographic interactions model (Model 2) for jelly products was found to be statistically significant with a $P$ value less than 0.001 indicated by a log likelihood ratio test. The model indicates that females were $\approx 1.30$ times more likely to select local and U.S. origin products than imported products when controlling for all other variables. Females were 1.15 times more likely to choose products with health claims relative to products without health claim. Females were $15 \%$ less likely to purchase a product with each unit increase in price compared with males. The inclusion of consumer income in the interactions model suggested reduced preference for the status quo grape jelly products with increasing income. Controlling for all other variables, with each unit increase in income category, there was a 5\% decrease in the likelihood of grape jelly products being purchased. The age of the consumer was also found to be a significant determinant of jelly product preference. Controlling for all other variables, for each unit increase in age, consumers were $13 \%$ less likely to purchase grape and $9 \%$ less likely to purchase elderberry jelly types relative to blackberry jelly. Results suggest that older 
consumers preferred products produced locally or in the United States over imports. With each unit increase in age, consumers were $\approx 1.17$ times more likely to purchase local products or products of U.S. origin relative to products that were imported.

Consumer elderberry juice preferences. Table 3 presents the results of the conditional logit model for survey Version 2 (juice products). The model included 12,759 observations and was found to be statistically significant with a $P$ value less than 0.001 as indicated by the likelihood ratio test. The regression found all variables to be significant with a $P$ value less than 0.001 .

The attribute levels of the elderberry fruit type or the increase in price resulted in negative coefficients. Based on model coefficients, when the product was identified as being made from elderberry or had a $\$ 1$ unit increase in price, there was a correlated decrease in the likelihood of that product being chosen. Stated purchase preference for products made from elderberry was $23 \%$ lower than products made from pomegranate. For every $\$ 1$ increase in price, the odds of that product being purchased decreased by $54 \%$, ceteris paribus.

The attribute levels for products produced locally, in the United States, having a health claim, or made from cranberry had positive coefficient values. Products produced locally were 3.3 times more likely to be purchased than imported products, ceteris paribus. U.S.-produced products were 2.39 times more likely to be chosen than imported products. Products with health claims were two times more likely to be selected than those without health claims. The RI was greatest for the price of the product $(38 \%)$ followed by the origin of the product $(30 \%)$ and health claims (19\%); the least important factor was the type of fruit from which the product was made $(13 \%)$.

Model 2, which controlled for demographic effects on juice product preferences, was found to be statistically significant with a $\log$ likelihood ratio test $P$ value less than 0.001 . Female consumers were found to prefer products of local or U.S. origin $\approx 1.30$ times more than imported products when controlling demographic variables. Females were 1.32 times more likely to purchase products with health claims relative to products without health claims when controlling for demographic variables. Income effects were not statistically significant when comparing preferences for pomegranate and elderberry juice. However, conditional logit results suggest that higher levels of income were associated with greater preferences for cranberry juice $(P<$ $0.10)$ over pomegranate juice. The age of the consumer was found to be a determinant of preference as well. Controlling for all other variables, each unit increase in consumer age meant they were 1.12 times more likely to purchase a product of local or U.S. origin compared with imported products.

Potential market share scenarios. Figure 2 illustrates the first market scenario, which compared the estimated shares for elderberry juice and jelly products with health claims and of local origin with market shares for imported products with health claims. The elderberry product option was compared against the status quo and competitive product options, both priced consistently at a base level of $\$ 4$, and with all products including a health claim. Model estimates indicate that when priced at the base level (\$4), locally produced jelly and juice products comprised $50 \%$ and $40 \%$ of the total market, respectively. Products that were imported, when priced equally, composed a much smaller share of the market (jelly $22 \%$ and juice $18 \%$ ). By comparison, the marginal effect of a health claim was responsible for a $28 \%$ increase and a $20 \%$ increase in jelly and juice market share, respectively. When juice and jelly products were compared at $\$ 5$, which represented a $25 \%$ price premium above the $\$ 4$ base price, jelly and juice products of local origin constituted $36 \%$ and $25 \%$ of the total market, respectively, whereas imported jelly products composed $13 \%$ and juice $9 \%$ of the total market. As the product price premium increased, the percent market share for juice and jelly products decreased along with the marginal difference in preference for local products relative to imported products.

Figure 3 illustrates a comparison of market shares for juice and jelly products produced locally. The scenario compared juice and jelly products produced locally that disclosed health claims against juice and jelly

Table 2. Results of the elderberry jelly conditional logit regression indicating consumer preference for product attributes and relative importance.

\begin{tabular}{|c|c|c|c|c|c|c|c|c|c|}
\hline \multirow[b]{2}{*}{ Jelly attributes and levels } & \multicolumn{5}{|c|}{ Model 1: Product attributes } & \multicolumn{4}{|c|}{ Model 2: Product attributes and demographic characteristics } \\
\hline & Coefficient & $\mathrm{SE}$ & $P>\mathrm{z}$ & Odds ratio & RI & Coefficient & SE & $P>\mathrm{z}$ & Odds ratio \\
\hline Elderberry $2 * * *$ & -0.309 & 0.040 & 0.001 & 0.734 & & 0.020 & 0.128 & 0.877 & 1.020 \\
\hline Origin of production ${ }^{y}$ & & & & & $37.09 \%$ & & & & \\
\hline Local*** & 1.304 & 0.060 & 0.001 & 3.682 & & 0.691 & 0.191 & 0.001 & 1.996 \\
\hline USA $* * *$ & 1.014 & 0.065 & 0.001 & 2.758 & & 0.398 & 0.205 & 0.052 & 1.489 \\
\hline Elderberry_female & & & & & & -0.024 & 0.081 & 0.766 & 0.976 \\
\hline Grape_female & & & & & & -0.135 & 0.112 & 0.230 & 0.874 \\
\hline Local_female** & & & & & & 0.237 & 0.123 & 0.054 & 1.268 \\
\hline USA_female* & & & & & & 0.227 & 0.132 & 0.086 & 1.255 \\
\hline Health claim female* & & & & & & 0.139 & 0.081 & 0.086 & 1.150 \\
\hline Price_female ${ }^{* * *}$ & & & & & & -0.160 & 0.056 & 0.004 & 0.852 \\
\hline Elderberry_income & & & & & & 0.006 & 0.011 & 0.602 & 1.006 \\
\hline Price_income & & & & & & 0.009 & 0.007 & 0.223 & 1.009 \\
\hline Elderberry_age*** & & & & & & -0.094 & 0.025 & 0.001 & 0.910 \\
\hline Grape_age*** & & & & & & -0.138 & 0.035 & 0.001 & 0.871 \\
\hline USA_age*** & & & & & & 0.156 & 0.038 & 0.001 & 1.169 \\
\hline Local_age*** & & & & & & 0.155 & 0.041 & 0.001 & 1.167 \\
\hline Health claim_age & & & & & & 0.011 & 0.025 & 0.660 & 1.011 \\
\hline Price_age*** & & & & & & -0.044 & 0.017 & 0.011 & 0.957 \\
\hline
\end{tabular}

Total number of entries $(\mathrm{n})=13,548 . \mathrm{RI}=$ relative importance. Log likelihood ratio test: -4319.211 . Prob $>\chi^{2}<0.001$ in product attributes-only model. Log likelihood ratio test: -4231.365 . Prob $>\chi^{2}<0.001$ in the demographic effects model.

${ }^{\mathrm{z}}$ Base product attribute for comparison: blackberry jelly.

${ }^{\mathrm{y} B}$ Base product attribute for comparison: imported.

${ }^{\mathrm{x}}$ Base product attribute for comparison: without health claim.

$* * * P<0.01, * * P<0.05, * P<0.10$. 
Table 3. Results of the elderberry juice conditional logit regression indicating consumer preference for product attributes and relative importance.

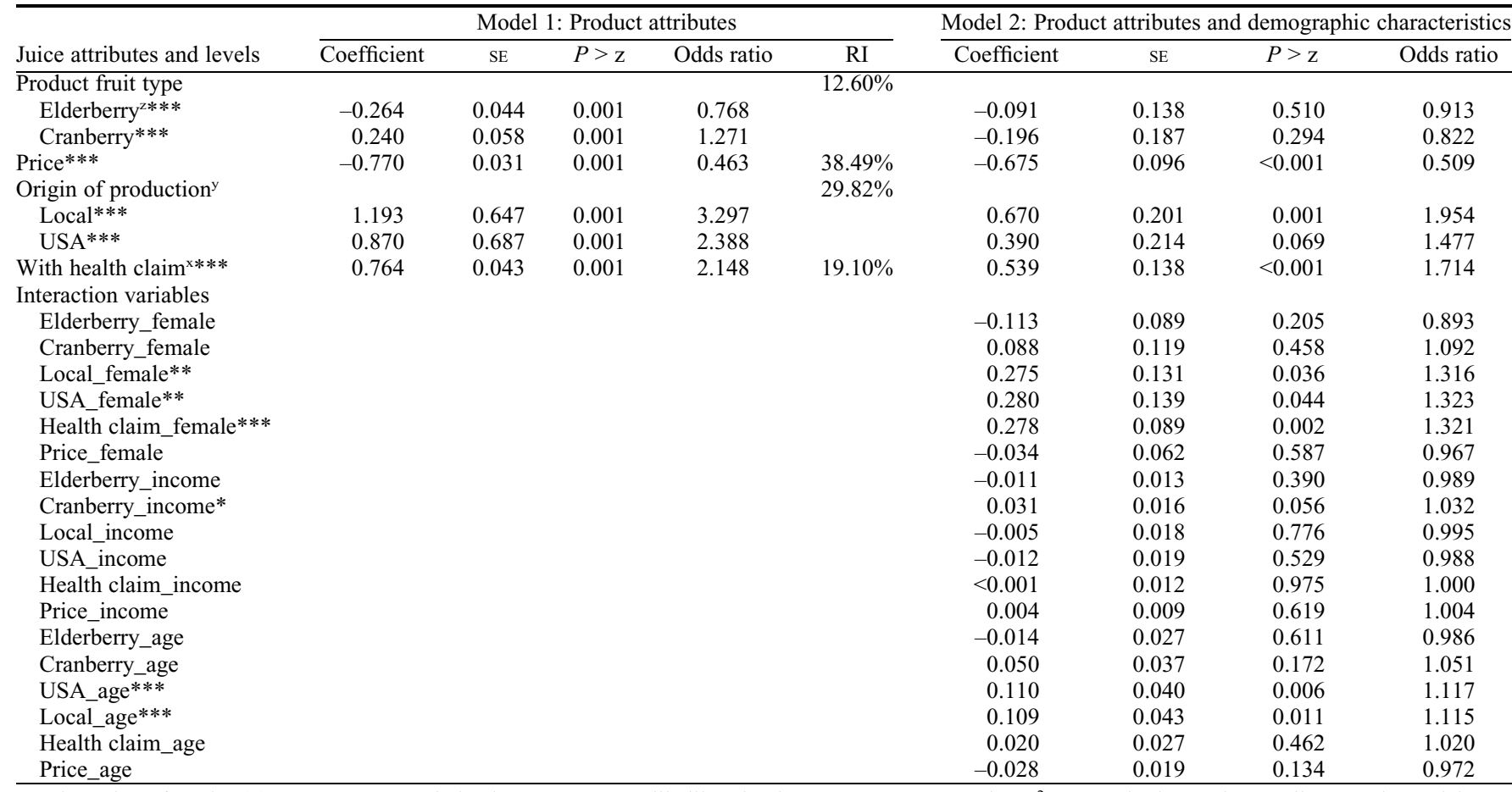

Total number of entries $(\mathrm{n})=12,759 . \mathrm{RI}=$ relative importance. Log likelihood ratio test: -4060.623 . Prob $>\chi^{2}<0.001$ in the product attributes-only model. Log likelihood ratio test: -4026.989 . Prob $>\chi^{2}<0.001$ in the demographic effects model.

${ }^{\mathrm{z} B}$ Base product attribute for comparison: pomegranate juice.

${ }^{\mathrm{y} B a s e}$ product attribute for comparison: imported.

${ }^{\mathrm{B}}$ Base product attribute for comparison: without health claim.

$* * * P<0.01, * * P<0.05, * P<0.10$.

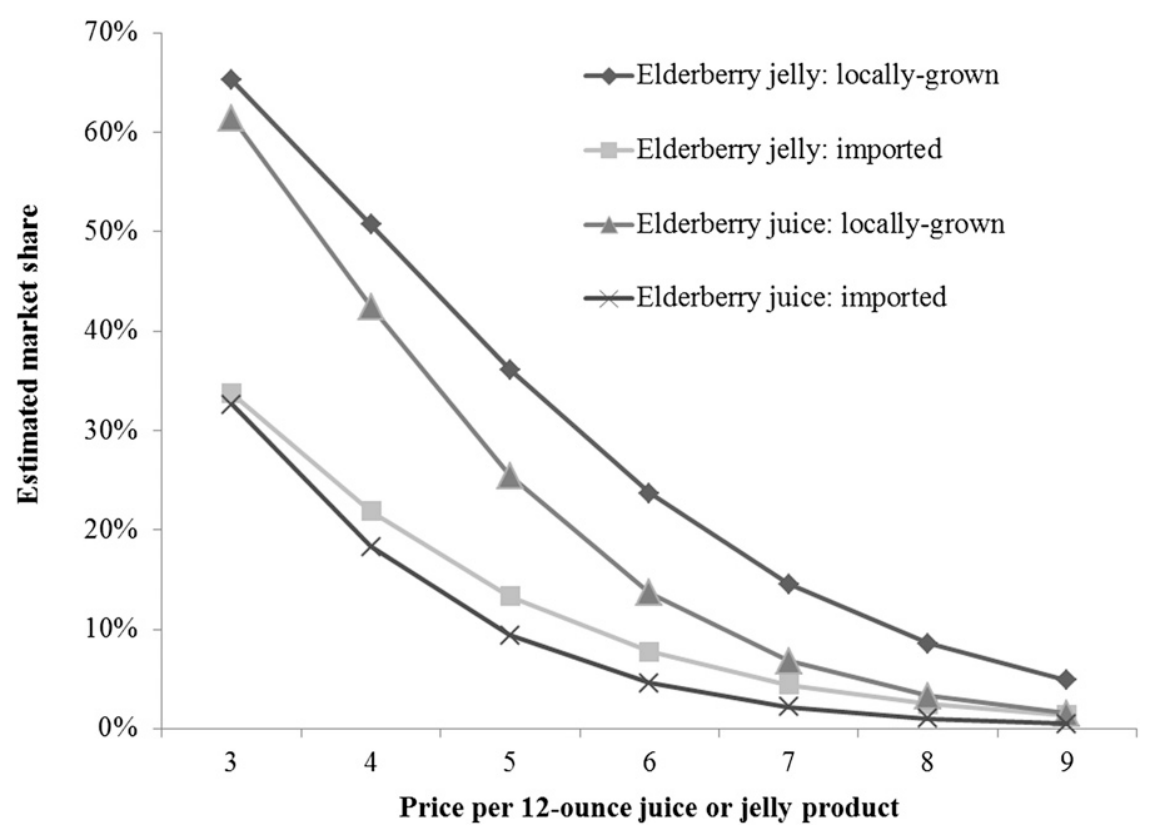

Fig. 2. Scenario 1 comparing the market share at one dollar price increments for elderberry juice and jelly products with health claims that have been produced locally against those that have been imported. All comparisons made against the status quo base price of $\$ 4$ per unit of 12-ounce jar/bottle.

products that did not advertise such claims holding other attributes constant. Like the previous scenario, the elderberry product option was compared against two product alternatives (competitive and status quo), which were consistently priced at the base level of $\$ 4$ per 12-ounce unit and all products were produced locally. Results indicate that when products were priced at $\$ 4$, elderberry jelly and juice products that advertised health claims comprised a greater market share than products without health claims. At $\$ 4$ per unit, elderberry composed $36 \%$ and $32 \%$ of the jelly and juice markets, respectively. At the same price, however, elderberry products without health claims comprised a much smaller portion of the market $(21 \%$ and $18 \%$ of the jelly and juice markets, respectively). By comparison, marginal effects for products disclosing a health claim benefit, when priced at $\$ 4$, resulted in $15 \%$ and $14 \%$ increases in stated choice preferences for jelly and juice. When the juice and jelly products were compared at $\$ 5$, a $25 \%$ price premium, jelly products captured $18 \%$ and $24 \%$ of jelly and juice markets, respectively. At this same price, but without health claims, shares dropped to $13 \%$ and $9 \%$. This demonstrates that including a qualified health claim on the label has the potential to offset negative effects of price premiums. As the price premium for elderberry juice and jelly increased, market shares decreased along with the beneficial marginal effects of the health claim compared with products without health claims as illustrated on Figure 3.

\section{Discussion}

Results of the attribute-only models for jelly and juice products support the preference that consumers have for local and U.S.produced products over imported ones. In both jelly and juice models, the origin of the product played a greater role in determining preference than the type of fruit in the product and the disclosure of a qualified health claim. The high value that consumers placed on 


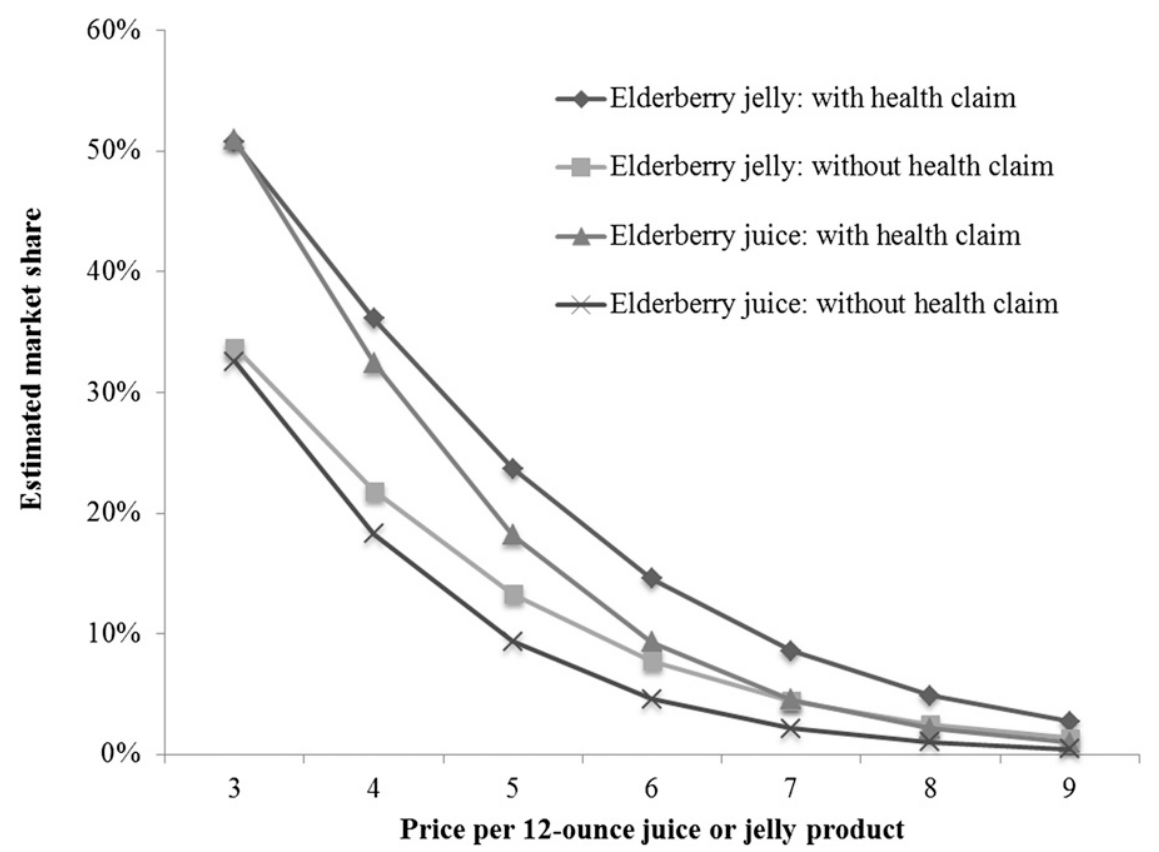

Fig. 3. Scenario 2 comparing the market share at one dollar price increments for elderberry juice and jelly products produced locally that advertise health benefit claims against products that do not advertise health benefit claims holding all other attributes constant and with all comparisons made against the status quo base price of $\$ 4$ per unit of 12 -ounce jar/bottle.

local foods is not distinctive to the jelly and juice industry; it has been recorded in a number of marketing studies for a diverse variety of products (Loureiro and Hine, 2002; Yue et al., 2011; Yue and Tong, 2009). In addition to importance of the product's origin, price also played a significant role in stated preferences. After the price and origin of the product, health claim disclosure was found to be an important factor for consumer jelly and juice product purchasing with consumers consistently preferring products with health claims over products without health claims. The growing popularity of foods that promote health benefits is well supported in diverse marketing studies including Kozup et al. (2003) and Verbeke (2005).

The results of the study suggest female consumers of elderberry jelly and juice preferred local and U.S.-produced products over imported products. Female consumer preference for local foods has been noted in numerous studies. Loureiro and Umberger (2003) in a survey of 243 U.S. consumers found females to be more likely to pay premium prices for beef products carrying mandatory country of origin labeling programs. Nayga et al. (1995) also suggested that females in New Jersey were more likely to frequent direct markets (i.e., markets that sell directly from farmers to consumers like roadside stands, farmers' markets, pick-yourown, community-supported agriculture) than males. In a study of consumer preferences for locally grown foods in southeast Missouri, Brown (2003) found female consumers more likely to pay higher prices for local food than males. Zepeda and Li (2006) reported a greater likelihood among females to purchase local foods as a function of household size and gender role in families. Households of more than one individual and individuals who stated they "enjoy cooking" were significantly more likely to purchase local foods.

The results of this study did not find the income of the respondent to be a significant determinant in purchasing decisions with the exception of grape jelly that exhibited an inverse relation with income. Although income was not found to be a common determinant of preferences, numerous marketing studies have indicated the effects of income on consumer preferences (Childs, 1997; Teratanavat and Hooker, 2005). In a study of consumer produce preference, Yue and Tong (2009) did not find consumers' income to be a significant determinant of locally grown food preferences but instead found it to be significant for organically grown foods. Consistent with the result of this study, Yue and Tong (2009) indicate that preference for local foods has not caught the attention of the public in the way that the term "organic" has in publication. Locally grown foods remain accessible to consumers of all income levels and are not yet seen as a specialty good only affordable to wealthier consumers. Padel (2006) in a study of consumer perceptions of organic food found a strong association of "organic food" and "locally grown." This association can result in their meanings being confused or intertwined. More research is needed to fully support this assertion and better understand consumer perceptions of locally grown foods. In this study, nonetheless, because we did not distinguish between organic and locally grown attributes in the CA. we were not able to discern any problems related to this potential issue.
The results of the study found age to be a significant determinant of consumer preference for local products. Older consumers were significantly more likely to prefer locally or U.S.-produced products over imported products. This finding is supported by Bruhn et al. (1992) in a survey of produce consumers at supermarkets, which found that older customers place a significantly higher importance on their produce being grown locally than younger consumers. However, more recent reports have not found a consistent correlation between age and locally produced products (Brown, 2003). Research has also found that middle and higher age bracket consumers are more likely to frequent farmers' markets than young consumers (Kezis et al., 1998; Wolf, 1997).

The results of the study are the first of their kind in that they gathered market intelligence on the consumer preferences for elderberry jelly and juice products. The information generated from this study can be used to devise marketing strategies to motivate consumer choice. Consumers placed a high value on importance of and preference for products that disclose information about local origin and health benefits. Although consumers' choices of jelly and juice elderberry products were highly sensitive to price changes, the results presented in Figures 2 and 3 indicate that the inclusion of local origin and health claim labels could ameliorate this effect and help elderberry products capture significant shares of their respective markets.

\section{Conclusions}

Participants identified origin $(37 \%)$ and price $(34 \%)$ as the two most important attributes when choosing jelly products from a bundle that included price, origin, fruit type, and qualified health claims. When selecting juice products, participants identified price $(38 \%)$ followed by origin $(30 \%)$ as the two most important product attributes. The high level of importance that consumers placed on jelly and juice product prices suggests the need for elderberry firms to design pricing strategies that are competitive with products already established in their respective markets. When a firm is unable to place an elderberry product on the shelf that is priced competitively, the best strategy for that firm would be to emphasize local origin. The addition of the locally grown or produced attribute to the product may attract consumers even when the product is offered at a higher price than the alternative fruit type. Consumers of jelly products were less sensitive to price changes, suggesting that elderberry jelly products may be offered at a premium and remain competitive in current markets. Because participants were more sensitive to changes in price of juice products, a more conservative price strategy would be required when introducing elderberry juice in the U.S. market.

Participants were $27 \%$ less likely to choose elderberry and $20 \%$ less likely to select grape jellies compared with blackberry 
holding other product attributes constant. In the survey version evaluating juice product preferences, participants were also $23 \%$ less likely to choose elderberry compared with pomegranate juice and 1.3 times more likely to purchase cranberry juice. These results indicate that the average U.S. consumer, the majority of whom have not sampled or tasted an elderberry product, may have a preference for the status quo or most popular product in the market. The preference of average U.S. consumers toward the selection of grape jelly can be restructured by promoting elderberry products' local origins and substantiated health benefits. Study participants, although reluctant to select products containing elderberry, were 3.7 times more likely to choose local jelly products and 3.3 times more likely to choose local juice products than imported ones. Consumers were also twice as likely to choose jelly products that advertised qualified health claims and 2.1 times more likely to select juice products with health claims than products without such claims. There is also indication that higher income consumers may be more likely to choose elderberry over grape jelly, which points to a potential market niche for the former.

Given current consumers' perceptions of elderberry products, an initial market placement strategy should follow an effective information and pricing approach. An introductory strategy should emphasize and widely disseminate the health benefits of elderberry as has been the case with cranberry products. Marketing strategies that advertise local elderberry production and natural health benefits while being pricecompetitive can help build new elderberry consumption habits and increase elderberry jelly and juice market shares. Our results suggest that higher income consumers would be a natural segment to target as they may move away from status quo products ( jelly in particular) and seek exotic fruit products that also offer health benefits. The prospects of price premiums that may be captured when origin and health claims can be disclosed also provide an incentive to target elderberry products in specialty stores and aisles in mainstream grocery shops. Production costs aside, the capacity of a growing elderberry industry to compete in jelly and juice markets and capture price premiums will likely be dependent on firms' ability to effectively communicate health benefits of their products and use locally sourced fruits.

\section{Literature Cited}

Aguilar, F.X. and Z. Cai. 2010. Conjoint effect of environmental labeling: Disclosure of forest of origin and price on consumer preferences for wood products in the U.S. and U.K. Ecol. Econ. 70:308-316.

Aguilar, F.X., M.M. Cernusca, and M.A. Gold. 2009a. Exploratory assessment of consumer preferences for chestnut attributes in Missouri. HortTechnology 19:206-223.

Aguilar, F.X., M.M. Cernusca, M.A. Gold, and C.E. Barbieri. 2009b. Frequency of consumption and preferences for chestnuts in Missouri. Agrofor. Syst. 79:19-29.
Anderson, S., A. de Palma, and J. Thisse. 1992. Discrete choice theory of product differentiation. MIT Press, Cambridge, MA.

Baker, G.A. 1999. Consumer preferences for food safety attributes in fresh apples: Market segments, consumer characteristics, and marketing opportunities. J. Agr. Resource Econ. 24:8097.

Baker, G.A. and T.A. Burnham. 2001. Consumer response to genetically modified foods: Market segment analysis and implications for producers and policy makers. J. Agr. Resource Econ. 26:387-403.

Barak, V., S. Birkenfeld, T. Halperin, and I. Kalickman. 2002. The effect of herbal remedies on the production of human inflammatory and anti-inflammatory cytokines. Israel Medical Assn. J. 4(Suppl.11):919-922.

Brown, C. 2003. Consumers' preferences for locally produced food: A study in southeast Missouri. Amer. J. Altern. Agr. 18:213-224.

Bruhn, C.M., P.M. Vossen, E. Chapman, and S. Vaupel. 1992. Consumer attitudes toward locally grown produce. Calif. Agr. 46:13-16.

Cernusca, M.M., M.A. Gold, and L.D. Godsey. 2011. Using the Porter model to analyze the U.S. elderberry industry. Proc. 12th North Amer. Agrofor. Conf., Athens, GA. 4-9 June 2011. p. 191-200.

Charlebois, D., P. Byers, C. Finn, and A. Tomas. 2010. Elderberry: Botany, horticulture, potential. Hort. Rev. 37:213-280.

Childs, M. 1997. Functional foods and the food industry: Consumer, economic and product development issues. J. Nutraceuticals. Funct. Med. Foods 1:25-43.

Chunrong, A. and E. Norton. 2003. Interaction terms in logit and probit models. Econletters 80:123-129.

Dolan, R.J. 2001. Analyzing consumer preferences. Harvard Business Review. Note 599 112. Boston, MA.

Glanz, K., M. Basil, E. Maibach, J. Goldberg, and D. Snyder. 1998. Why Americans eat what they do: Taste, nutrition, cost, convenience, and weight control concerns as influences on food consumption. J. Amer. Diet. Assoc. 98:1118-1126.

Green, P. and V. Srinivasan. 1990. Conjoint analysis in marketing: New developments with implications for research and practice. J. Mktg. 54:3-19.

Harrison, R.W., T. Stringer, and W. Prinyawiwatkul. 2002. An analysis of consumer preferences for value-added seafood products derived from crawfish. Agr. Resource Econ. Rev. 31:157-170.

Horowitz, J.L. and J.J. Louviere. 1993. Testing predicted choices against observations in probabilistic discrete-choice models. Mktg. Sci. 12:270-279.

Hu, W., T. Woods, and S. Bastin. 2009. Consumer acceptance and willingness to pay for blueberry products with nonconventional attributes. J. Agr. Appl. Econ. 41:47-60.

Kezis, A., T. Gwebu, S. Peavey, and H.T. Cheng. 1998. A study of consumers at a small farmers' market in Maine: Results from a 1995 survey. J. Food Distrib. Res. 29:91-99.

Kozup, J.C., E.H. Creyer, and S. Burton. 2003. Making healthful food choices: The influence of health claims and nutrition information on consumers' evaluation of packaged food products and restaurant menu items. J. Mktg. 67:1934.

Lee, J. and C.E. Finn. 2007. Anthrocyanins and other polyphenolics in American elderberry (Sambucus canadensis) and European elderberry (S. nigra) cultivars. J. Sci. Food Agr. 87: 2665-2675.
Long, J.S. and J. Freese. 2006. Regression models for categorical dependent variables using Stata. Stata Press, College Station, TX.

Lonial, S., D. Menezes, and S. Zaim. 2000. Identifying purchase driving attributes and market segments for PCs using conjoint and cluster analysis. J. Econ. Soc. Res. 2:19-37.

Loureiro, M. and S. Hine. 2002. Discovering niche markets: A comparison of consumer willingness to pay for local (Colorado grown), organic, and GMO-free products. J. Agr. Appl. Econ. 34:477-487.

Loureiro, M. and W. Umberger. 2003. Estimating consumer willingness to pay for country of origin labeling. J. Agr. Res. Econ. 28:287-301.

Louviere, J.J., T. Flynn, and R. Carson. 2010. Discrete choice experiments are not conjoint analysis. J. Choice Modeling 3:57-72.

Louviere, J.J., D.A. Hensher, and J.D. Swatt. 2000. States choice methods. University Press, Cambridge, MA.

McFadden, D. 1974. Conditional logit analysis of quantitative choice behavior. In: Zarembka, P. (ed.). Frontiers in econometrics. Academic Press, New York, NY.

McFadden, D. 1986. The choice theory approach to market research. Mktg. Sci. 5:275-297.

Mintel Group. 2010. Savory and sweet spreads: The market-U.S. 21 Feb. 2011. <http://academic. mintel.com>.

Mintel Group. 2011. Juice and juice drinks: The market-U.S. 21 Feb. 2011. <http://academic. mintel.com>.

Mohebalian, P. 2011. U.S. consumer preference for elderberry products. MS thesis, University of Missouri, Columbia, MO.

Nayga, R.M., Jr., Govindasamy, T.C. Wall, and D.W. Thatch. 1995. Characteristics of farmerto-consumer direct market customers in New Jersey. New Jersey Agricultural Experiment Station Publication No. P-02136-3-95, Department of Agricultural Economics and Marketing, Rutgers University Cooperative Extension, New Brunswick, NJ.

Padel, S. 2006. Local and/or organic: A balancing of values for producers and consumers. Farmers Weekly 6:28-31.

Rambonilaza, M. and J. Dachary-Bernard. 2007. Land-use planning and public preferences: What can we learn from choice experiment method? Landsc. Urban Plan. 83:318-326.

Roschek, B., R.C. Fink, M.D. McMichael, D. Li, and R.S. Alberte. 2009. Elderberry flavonoids bind to and prevent H1N1 infection in vitro. Phytochemistry 70:1255-1261.

SAS Institute Inc. 2008. Getting started with SAS 9.2 ADX interface for design or experiments. SAS Institute Inc., Cary, NC.

Simonne, A.H., B.K. Behe, and M.M. Marshall. 2006. Consumers prefer low-priced and high lycopene-content fresh-market tomatoes. HortTechnology 16:674-681.

Teratanavat, R. and N. Hooker. 2005. Exploring consumer valuation and preference heterogeneity for functional foods using a choice experiment: A case study of tomato juice containing soy in Ohio. Proc. Amer. Agr. Econ. Assn. Annu. Mtg. Paper No. 19556. 21 May. 2012. <http://ageconsearch. umn.edu/bitstream/19556/1/sp05te03.pdf >.

Thurstone, L. 1927. The method of paired comparisons for social values. J. Abnorm. Soc. Psychol. $21: 384-400$

Uncini Manganelli, R.E., L. Zaccaro, and P.E. Tomei. 2005. Antiviral activity in-vitro of Urtica dioica L., Parietaria diffusa and Sambucus nigra L. J. Ethnopharmacol. 98:323-327.

U.S. Census Bureau. 2000. American fact finder. 11 Sept. 2011. <http://www.census.gov>. 
U.S. Centers for Disease Control and Prevention. 2010. Diseases and conditions. 7 Aug. 2010. $<$ http://www.cdc.gov>.

USDA Agriculture Research Service. 2007. Oxygen radical absorbance capacity (ORAC) of selected foods. 16 Aug. 2010. <http://www.ars. usda.gov/nutrientdata>.

USDA Economic Research Service. 2010. Local food systems: Concepts, impacts and issues. 15 Dec. 2011. <http://www.ers.usda.gov/ Publications/ERR97/ERR97.pdf $>$.

Veisten, K. 2007. Willingness to pay for ecolabeled wood furniture: Choice-based conjoint analysis versus open-ended contingent valuation. J. For. Econ. 13:29-48.

Verbeke, W. 2005. Consumer acceptance of functional foods: Socio-demographic, cognitive and attitudinal determinants. J. Food Qual. Prefer. 16:45-57.

Wessells, C.R., R.J. Johnston, and H. Donath. 1999. Assessing consumer preferences for eco-labeled seafood: The influence of species certifier and household attributes. Amer. Agr. Econ. Assoc. 81:1084-1089.

Wolf, M. 1997. A target consumer profile and positioning for promotion of the direct marketing of fresh produce: A case study. J. Food Distrib. Res. 28:11-17.

Yue, C., J. Dennis, B. Behe, C. Hall, B. Campbell, and R. Lopez. 2011. Investigating consumer preferences for organic, local, or sustainable plants. HortScience 46:610-615.

Yue, C. and C. Tong. 2009. Organic or local? Investigating consumer preference for fresh produce using a choice experiment with real economic incentives. HortScience 44:366371.

Zepeda, L. and J. Li. 2006. Who buys local foods? J. Food Distrib. Res. 37:1-14. 